\title{
A Simple Strategy for the Simultaneous Determination of Dopamine, Uric Acid, L-Tryptophan and Theophylline Based on a Carbon Dots Modified Electrode
}

\author{
Ziwei Wang, Rui An, Yuxuan Dai, Hongxia Luo* \\ Department of Chemistry, Renmin University of China, Beijing 100872, China \\ *E-mail: $\underline{\text { luohx@ ruc.edu.cn }}$ \\ doi: $10.20964 / 2021.04 .39$
}

Received: 2 December 2020 / Accepted: 27 January 2021 / Published: 28 February 2021

\begin{abstract}
In this work, carbon dots (CDs) were produced by one-step ultrasound technology with glucose as the precursor. The effective synthesis of CDs was characterized by Raman spectroscopy and UV-visible spectra. The as-prepared CDs were fixed on a glassy carbon electrode (GCE) via electrochemical deposition to fabricate CDs/GCE, which simultaneously detected dopamine (DA), uric acid (UA), Ltryptophan (Trp) and theophylline (TP). With the differential pulse voltammetry technique, the oxidation peak currents of these four biomolecules were significantly enhanced on CDs/GCE compared to those on bare GCE. The potential differences of DA-UA, UA-Trp, and Trp-TP were computed as $145 \mathrm{mV}$, $381 \mathrm{mV}$, and $323 \mathrm{mV}$, respectively. The broad linear ranges were $0.5-50 \mu \mathrm{M}$ for $\mathrm{DA}, 3-75 \mu \mathrm{M}$ for UA, 1-65 $\mu \mathrm{M}$ for Trp and 10-200 $\mu \mathrm{M}$ for TP with limits of detection (LODs) of $0.007 \mu \mathrm{M}, 0.011 \mu \mathrm{M}, 0.11$ $\mu \mathrm{M}$ and $0.33 \mu \mathrm{M}(\mathrm{S} / \mathrm{N}=3)$, respectively. The CD/GCE sensor had good stability and strong antiinterference ability and was applicable to detecting actual samples.
\end{abstract}

Keywords: Carbon dots; Glassy carbon electrode; Electrochemical sensing; Dopamine; Uric acid; Ltryptophan; Theophylline

\section{FULL TEXT}

(C) 2021 The Authors. Published by ESG (www.electrochemsci.org). This article is an open access article distributed under the terms and conditions of the Creative Commons Attribution license (http://creativecommons.org/licenses/by/4.0/). 